\title{
O jogo político do Fundo de Financiamento Estudantil (FIES) (2010-2016)
}

\author{
Aline Veiga dos Santos' (1) \\ Vera Lúcia Jacob Chaves" (D) \\ Divaneide Lira Lima Paixão"I (D
}

\section{RESUMO}

Este artigo analisa o financiamento do Ensino Superior privado por meio do Fundo de Financiamento Estudantil (FIES), que está inserido em uma complexa teia de articulações entre Estado e empresariado. Examinam-se os discursos de deputados e senadores sobre o FIES e a articulação do setor privado-mercantil com esses atores políticos. Trata-se de uma pesquisa documental crítico-descritiva, baseada na teoria do Estado ampliado e no método da análise de redes sociais. Os dados foram submetidos ao software Analyse Lexicale par Contexte d'un Ensemble de Segments de Texte. O FIES é uma política pública de caráter social, que se desenvolveu atendendo aos interesses dos empresários da educação. Constatou-se que se tornou uma política de mercado deliberada nos bastidores do Congresso Nacional, com repasses anuais bilionários para as Instituições de Ensino Superior privado-mercantis, e contribuiu para o processo de expansão, mercantilização e financeirização do Ensino Superior privado-mercantil.

\section{PALAVRAS-CHAVE}

Fundo de Financiamento Estudantil; atores políticos; setor privado-mercantil; financeirização.

'Universidade Católica de Brasília, Brasília, DF, Brasil.

"Universidade Federal do Pará, Belém, PA, Brasil.

"'Secretaria de Estado de Educação do Distrito Federal, Brasília, DF, Brasil. 


\section{THE POLITICAL GAME OF THE STUDENT FINANCING FUND (FIES) (2010-2016)}

\section{ABSTRACT}

This paper analyses the financing of the private higher education, through the Student Financing Fund (FIES), which inserted in a complex web of articulations between the State and the business community. We examine the speeches of deputies and senators about the FIES and the articulation of the private-mercantile sector with these political actors. This is a critical-descriptive documentary research, based on the theory of the expanded State and the method of the analysis of social networks. The data was submitted to the software Analyse Lexicale par Contexte d'un Ensemble de Segments de Texte. FIES is a public policy of social character, that was developed taking into account the interests of the education entrepreneurs. It was found that became a deliberate market policy behind the scenes of the National Congress with annual billionaire transfers to the institutions private-mercantile; and contributed to the process of expansion, commodification and financialization of private-mercantile higher education.

\section{KEYWORDS}

Student Financing Fund; political actors; private-mercantile sector; financialization.

\section{EL JUEGO POLÍTICO DEL FONDO BRASILEÑO DE FINANCIAMIENTO ESTUDIANTIL (FIES) (2010-2016)}

\section{RESUMEN}

Este artículo analiza el financiamiento de la educación superior privada, a través del Fondo Brasileño de Financiamiento Estudiantil (FIES), que se insiere en una compleja red de articulaciones entre el Estado y el empresariado. Se examinan los discursos de diputados y senadores sobre el programa y la articulación del sector privado-mercantil con estos actores políticos. Se trata de una investigación documental crítico-descriptiva, basada en la teoría del Estado ampliado y el método de análisis de redes sociales. Los datos fueron sometidos al software Analyze Lexicale por Contexte d'A Ensemble de Segments de Texte (Alceste). FIES es una política pública de carácter social que se ha desarrollado atendiendo a los intereses de los empresarios de la educación. Se constató que se tornó una política de mercado deliberada entre bastidores del Congreso Nacional con transferencias anuales billonarias para instituciones de educación superior privado-mercantiles. Además, contribuyó con el proceso de expansión, mercantilización y financiarización de la educación superior privada-mercantil.

\section{PALABRAS CLAVE}

Fondo Brasileño de Financiamiento Estudiantil; actores políticos; sector privadomercantil; financiarización. 


\section{INTRODUÇÃO}

O Fundo de Financiamento Estudantil (FIES) é uma política educacional situada em uma rede de governança que envolve diversos atores políticos e sociais. Seu estudo constitui uma empreitada complexa de números impressionantes. Em fevereiro de 2018, o programa contava com 1,9 milhão de estudantes (contratos ativos), 1.674 Instituições de Ensino Superior (IES) participantes, 984 mantenedoras $^{1}, 134$ documentos normatizadores e um custo anual em torno de $\mathrm{R} \$ 20$ bilhões. Nos anos de 2016 a 2018, o FIES se tornou o mote dos discursos dos presidentes Dilma Rousseff (2011-2016) e Michel Temer (2016-2018), de ministros, senadores e deputados, de empresários da educação, da mídia, de consultores e de associações devido à quantidade expressiva de contratos ativos, ao impacto nas contas do governo federal e à importância social do programa. Em 2015, diante de um cenário de retração econômica e de ajuste das contas públicas, foi estabelecida uma série de medidas restritivas inéditas. Houve um corte de $60 \%$ dos contratos em relação a 2014, fato esse que abalou o setor.

As dimensões social e financeira do FIES ficaram comprometidas, pois seu alcance e sua sustentabilidade fiscal têm sido questionados pela Controladoria Geral da União (CGU) e pelo Tribunal de Contas da União (TCU). Segundo o Ministério da Educação (MEC), grande parte dos beneficiários já cursava ou tinha condições financeiras de arcar com os custos do Ensino Superior. Diante disso, verifica-se que o crescimento dos contratos formalizados não atendeu às expectativas iniciais da política, que teve uma contribuição aquém do esperado em relação à ampliação de novas matrículas no setor (Brasil, 2017). Para ampliar a reflexão, é importante compreender o desenvolvimento do programa.

Em 1999, o MEC criou o FIES² em substituição ao Programa de Crédito Educativo para Estudantes Carentes (Creduc), extinto em 1998 devido ao alto índice de inadimplência. O FIES destina-se à concessão de financiamentos a estudantes regularmente matriculados em cursos superiores presenciais não gratuitos com avaliação positiva ${ }^{3}$ nos processos geridos pelo MEC. Na primeira década de vigência (2000-2009), o FIES foi uma política pouco expressiva, com cerca de

1 Pessoa Jurídica ou Pessoa Física responsável por garantir o funcionamento das instituições de ensino privadas por meio da arrecadação de recursos. No caso das instituições públicas, o governo (federal, estadual ou municipal) é o mantenedor.

2 Criado pela Medida Provisória no 1.827, de 27 de maio de 1999, regulamentado pelas Portarias MEC no 860, de 27 de maio de 1999, e no 1.386, de 15 de setembro de 1999 , pela Resolução CMN no 2.647, de 22 de setembro de 1999, e convertido em Lei no 10.260 , em 12 de julho de 2001.

3 O MEC analisa a qualidade das IES por meio do Índice Geral de Cursos (IGC), que é calculado pela média dos Conceitos Preliminares de Cursos (CPCs) do último triênio; do Exame Nacional de Desempenho dos Estudantes (Enade); e dos conceitos dos cursos de Mestrado e Doutorado atribuídos pela Coordenação de Aperfeiçoamento de Pessoal de Nível Superior (Capes) na última avaliação disponível. Além disso, o MEC analisa a distribuição dos estudantes entre os diferentes níveis de ensino. A avaliação é considerada positiva se a instituição adquiriu, no mínimo, o conceito 3 no IGC, em uma escala de 1 a 5. 
500 mil contratos. Em 2010, o "Novo FIES" passou por ajustes que culminaram no crescimento exponencial dos contratos e o tornaram uma política de ampla materialidade, com impacto direto no orçamento da União.

As mudanças de flexibilização das regras estão imbricadas com as demandas da rede de governança do FIES, que visualizou nessa política uma potencial ferramenta de lucro, captação de estudantes, ocupação de vagas ociosas e de consolidação do setor. No período de 2010 a 2016, foram assinados 2,39 milhões de contratos, suscitando um desembolso de recursos "da ordem de $\mathrm{R} \$ 67,1$ bilhões" (Brasil, 2017, p. 41). Com repasses anuais bilionários, as IES privado-mercantis, representadas pelas IES com fins lucrativos, passaram a despontar no rol das empresas que mais receberam dinheiro da União. "As matrículas FIES passaram de aproximadamente 5\% do total efetuado na rede privada, em 2009, para 39\%, em 2015”(Brasil, 2017,p. 2).Em quase duas décadas de vigência, foram realizados em torno de 2,9 milhões de financiamentos.

Estudos realizados sobre a política de financiamento estudantil no Brasil, com ênfase no FIES, apontam a importância social do programa ao possibilitar ao estudante carente a oportunidade de cursar a Graduação (Couto, 2008; Oliveira, 2008). Em que pese o caráter social, o FIES aprofunda o processo de mercantilização da Educação Superior (Sousa, 2008; Vituri, 2014) ao contribuir com a expansão desordenada do setor privado e fortalecer o segmento com recursos públicos diretos (Cruz, 2013; Silva, 2014; Xavier, 2016). Verifica-se que, a partir de 2011, houve uma relação causal entre o aumento desordenado do número de contratos e o aumento das mensalidades (Duarte, 2014). O programa não tem elementos claros que assegurem a permanência dos estudantes, podendo ser compreendido como uma "política de focalização" (Barros, 2014). Em 2015, devido à insustentabilidade do programa, foram estabelecidos critérios inéditos para restringir o número de contratos (Santos, 2015). A inadimplência dos estudantes gera uma grande dívida para o Estado (Moura, 2016; Santos Filho, 2016).

De modo geral, os estudos sobre o FIES se concentram na área da educação e concluem que, a despeito de ser um importante programa de subsídio financeiro aos estudantes, a própria operacionalização do programa o torna insustentável por longo prazo, devido ao volume bilionário de recursos públicos utilizados para fortalecer o setor privado de Ensino Superior e aos altos índices de inadimplência. Como consequência, esse programa contribuiu para intensificar a privatização desse nível de ensino no Brasil e a concepção de educação como mercadoria altamente lucrativa.

Visando compreender a trajetória de expansão vertiginosa do FIES no período de 2010 a 2016, este artigo teve como objetivo examinar o posicionamento de deputados e senadores em relação a essa política, assim como a articulação desses atores com o setor privado-mercantil. O texto está estruturado em três partes. A primeira apresenta o percurso metodológico. A segunda analisa as perspectivas, os consensos e as contradições que permeiam o FIES. A terceira expõe o resultado das análises.

\section{PERCURSO METODOLÓGICO}

Parte-se da Teoria do Estado Ampliado de Gramsci $(1986,2014)$ para compreender a complexa rede de financiamento marcada pela correlação de forças entre 
os atores que constituem o Estado. Essa teoria permite analisar a política pública para além do aparato exclusivo do Estado-Nação. Tanto o aparelho de governo (sociedade política) quanto o aparelho privado de hegemonia (sociedade civil) integram a estrutura do Estado, destaca Gramsci (1986). Nessa perspectiva, o Estado organiza-se em uma arena de conflitos, contradições e disputas entre classes antagônicas.

Trata-se de uma pesquisa documental crítico-descritiva, que emprega o método da Análise de Redes Sociais (ARS) para avaliar a dinâmica e a estrutura da rede de atores que compõem o FIES. Na arena desse programa, há um jogo político, cuja correlação de forças entre o Estado brasileiro e os aparelhos privados de hegemonia, nacionais e internacionais, altera bastante a concepção da educação como bem público.

Desde a criação do FIES até dezembro de 2016, foram aprovadas 134 normas referentes ao programa (Brasil, 2017). A partir de 2010, devido às mudanças nas regras, ao impacto nas contas do governo e ao grande interesse dos grupos educacionais privado-mercantis, o FIES passou a ser tema de destaque nos pronunciamentos dos deputados e senadores. A Tabela 1 apresenta a quantidade de matérias em tramitação na Câmara dos Deputados e no Senado Federal e a quantidade de discursos referentes ao FIES, no período de 2010 a 2016.

Tabela 1 - Congresso Nacional: matérias em tramitação e discursos referentes ao FIES.

\begin{tabular}{l|c|c|c|c}
\hline \multirow{2}{*}{ Ano } & \multicolumn{2}{|c|}{ Câmara dos Deputados } & \multicolumn{2}{c}{ Senado Federal } \\
\cline { 2 - 5 } & $\begin{array}{c}\text { Projetos de Lei (PL) e } \\
\text { Projetos de Decreto } \\
\text { Legislativo (PDL) }\end{array}$ & Discursos* & $\begin{array}{c}\text { Projetos de } \\
\text { Lei (PL) }\end{array}$ & Discursos* \\
\hline $\mathbf{2 0 1 0}$ & 3 & 176 & - & 18 \\
\hline $\mathbf{2 0 1 1}$ & 8 & 54 & - & 76 \\
\hline $\mathbf{2 0 1 2}$ & - & 10 & 2 & 27 \\
\hline $\mathbf{2 0 1 3}$ & 2 & 35 & 1 & 95 \\
\hline $\mathbf{2 0 1 4}$ & 4 & 59 & 1 & 39 \\
\hline $\mathbf{2 0 1 5}$ & 15 & 164 & 1 & 160 \\
\hline $\mathbf{2 0 1 6}$ & 3 & 144 & 1 & 259 \\
\hline Total & $\mathbf{3 5}$ & $\mathbf{6 4 2}$ & $\mathbf{6}$ & $\mathbf{6 7 4}$ \\
\hline
\end{tabular}

*Para fins de análise, foram considerados os discursos dos deputados, senadores e dos atores convidados para participarem das audiências públicas referentes ao FIES.

Fonte: adaptada de Senado Federal (2017) e Câmara dos Deputados (2010-2016).

Nesse período, nas duas Casas, foram contabilizados 41 projetos em tramitação e 1.297 discursos. O ano de 2016 teve o maior número de discursos (403), seguido do ano de 2015 (324). As mudanças restritivas instituídas em 2015 e 2016 mexeram com os interesses dos empresários da educação. A partir disso, a bancada que representa o setor privado passou a se mobilizar. Observa-se que os pronunciamentos estão relacionados, em grande parte, aos questionamentos sobre as mudanças restritivas no FIES 
(que promoveram grande alvoroço nas IES e preocupação nos estudantes) e à votação de Medidas Provisórias (MP) referentes à liberação de mais recursos para o programa.

Para analisar as negociações e as mediações entre os partidos políticos na Câmara dos Deputados e no Senado Federal, foi necessário fazer uma compilação dos Projetos de Lei (PL) e dos discursos, o que resultou em 418 páginas de material para análise. Esses dados foram examinados a partir do software Analyse Lexicale par Contexte d'un Ensemble de Segments de Texte (Análise Lexical por Contexto de um Conjunto de Segmentos de Texto - Alceste ${ }^{4}$ ), versão 4.8/2012. O Alceste foi desenvolvido para acolher as demandas decorrentes da utilização de multimétodos em pesquisa, com geração de volumes consideráveis de informações sobre determinado objeto de estudo, muito comum nas pesquisas quantitativas e qualitativas.

\section{TECENDO OS DISCURSOS: PERSPECTIVAS, CONSENSOS E CONTRADIÇÕES DA POLÍTICA DE FINANCIAMENTO ESTUDANTIL}

A partir do método da ARS, foi construída a rede de governança do FIES. A primeira fase (delimitação do conjunto de atores) é basilar para uma pesquisa que se insere no domínio da ARS. Diversos atores participam da rede de governança do FIES. Entre eles se destacaram: MEC; Fundo Nacional de Desenvolvimento da Educação (FNDE); Conselho Nacional de Educação (CNE); deputados e senadores (Congresso Nacional); Banco do Brasil (BB); Caixa Econômica Federal (CEF); TCU; CGU; Kroton; Associação Brasileira de Mantenedoras de Ensino Superior (ABMES); Sindicato das Entidades Mantenedoras de Estabelecimentos de Ensino Superior no Estado de São Paulo (Semesp); Federação Nacional das Escolas Particulares (Fenep); Associação Nacional dos Centros Universitários (Anaceu); Associação Nacional das Universidades Particulares (Anup); Fórum das Entidades Representativas do Ensino Superior Particular (Feresp $\left.{ }^{5}\right)$; Associação Brasileira para o Desenvolvimento da Educação Superior (Abraes); instituição financeira do Banco Mundial (International Finance Corporation - IFC); Sindicato Nacional dos Docentes das Instituições de Ensino Superior (Andes); Confederação Nacional dos Trabalhadores em Estabelecimentos de Ensino (Contee); e União Nacional dos Estudantes (UNE).

Observou-se que grande parte dos rumos dessa política é decidida e tecida no Congresso Nacional por intermédio dos deputados e senadores. Nos debates, nos plenários das duas Casas, Câmara dos Deputados e Senado Federal, ficaram visíveis as perspectivas sobre o FIES, assim como os consensos e as contradições.

4 Desenvolvido em 1979, na França, por Max Reinert, destina-se a auxiliar a interpretação do corpus textual. Em que pese ser um recurso informacional francês, é possível fazer a análise de textos em português, pois possui dicionário neste idioma.

5 Criado em 2008, o Feresp foi constituído a partir da conexão de cinco entidades, denominadas associadas fundadoras: ABMES, Associação Brasileira das Mantenedoras das Faculdades (Abrafi), Anaceu, Anup e Semesp. Em 2009, a Fenep passou a integrar esse fórum e, em 2015, o Sindicato das Entidades Mantenedoras de Estabelecimentos de Ensino Superior do Estado do Rio de Janeiro (Semerj). 
A fim de compreender esse cenário, utilizou-se o software Alceste para analisar a produção e a disseminação de informações e a criação de canais de comunicação entre a sociedade política (deputados e senadores), os agentes representantes do Estado (MEC, FNDE, Ministério do Planejamento e Ministério da Fazenda), da sociedade civil mercantil (Anup, Fenep, Anaceu — instituições que constituem o Feresp) e de entidades ligadas aos movimentos sindicais e estudantil (UNE, Contee, Andes e Federação de Sindicatos de Trabalhadores Técnico-administrativos em Instituições de Ensino Superior Públicas do Brasil - Fasubra). Destarte, foram objetos de análise as redes de atores que estão envolvidas com essa política.

Foram compilados todos os discursos dos deputados, senadores e convidados das Casas referentes ao FIES, no período de 2010 a 2016. O Alceste gerou um relatório detalhado com 168 páginas e identificou 429.531 palavras, sendo 15.601 palavras diferentes, com uma média aproximada de 42 ocorrências por palavra. De toda a informação do corpus de análise, o programa considerou o percentual de 99,42\% do discurso, revelando, assim, a riqueza de vocabulário no corpus.

O Alceste considerou uma frequência mínima de quatro vezes para a palavra ser analisada. $\mathrm{O}$ peso das palavras, indicado pelo coeficiente $\chi^{2}(\mathrm{Phi})$, está relacionado à sua ordem de importância dentro do discurso. Quanto maior o coeficiente, mais relações a palavra estabelece com outras palavras do discurso, formando os núcleos de significação. Os resultados extraídos dos discursos a partir da árvore de classificação descendente podem ser conferidos na Figura 1.

\section{Primeira Classificação Descendente}

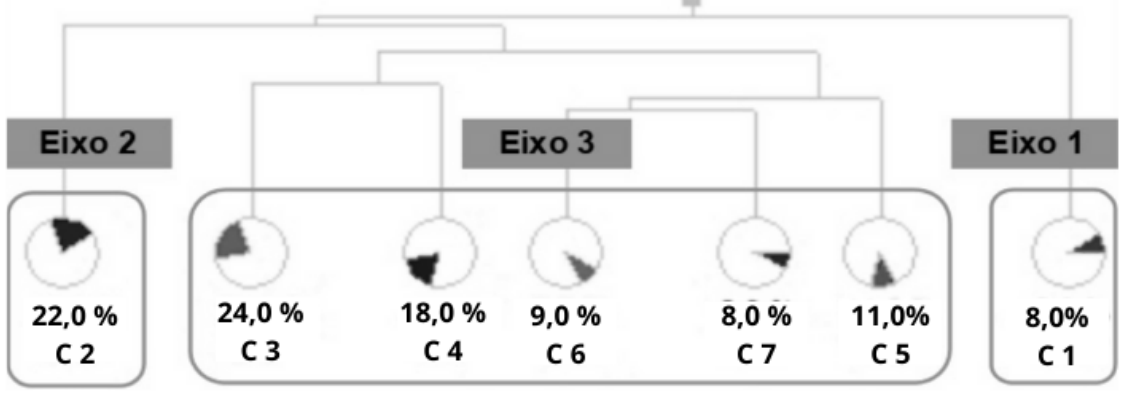

Figura 1 - Alceste: árvore de classificação descendente.

Fonte: adaptada de Alceste.

Os resultados apontaram a presença de sete classes distribuídas em três eixos. O primeiro eixo, denominado Procedimentos normativos e composto pela Classe 1 (C1), retrata os significados concernentes aos aspectos legais e normativos da formulação, criação e implementação dessa política. O Eixo 1 foca nos PL e PDL.

O segundo eixo, denominado Contexto de influência: momento de negociação entre os parlamentares e composto pela Classe 2 (C2), delineia o processo de ne- 
gociação entre os partidos políticos durante a votação das MP referentes ao FIES. Observa-se que foi dado destaque às $\mathrm{MP}$ destinadas à liberação de recursos para o FIES por se tratar de momentos de grande tensão.

O terceiro eixo, denominado Arena de governança: relações de força, poder, lobbies e contradições e composto pelas Classes 3, 4, 5, 6 e 7 (C3, C4, C5, C6 e C7), traz:

- as justificativas e contextualizações das mudanças radicais no programa, que impactaram em sua sustentabilidade, na permanência dos estudantes beneficiários e na promoção do acesso;

- debates sobre a importância do programa para o alcance da Meta 12 do Plano Nacional de Educação (PNE) - a ampliação dos benefícios e beneficiários do FIES;

- o desvelamento de irregularidades.

\section{EIXO 1: PROCEDIMENTOS NORMATIVOS}

O Eixo 1 é representado pelo menor percentual do corpus examinado pelo Alceste, com $8 \%$ do discurso. A análise da $\mathrm{C} 1$ está centrada no procedimento legal de formulação, criação e regulamentação do programa. As seis palavras mais representativas da C1 são: Projeto ( $\mathrm{phi}=72)$, Artigo (phi = 66), Vigorar ( $\mathrm{phi}=54)$, Lei $(\mathrm{phi}=49)$, Portaria $(\mathrm{phi}=35)$ e Normativa $(\mathrm{phi}=34)$. Esse conjunto de palavras destaca o rito sumário das duas Casas e tem relação direta com a constitucionalidade e pertinência ou não dos PL e PDL. O software destacou que o trecho mais representativo dessa Classe é:

É instituído, nos termos desta Lei, o Fundo de Financiamento Estudantil (FIES), de natureza contábil, destinado à concessão de financiamento a estudantes regularmente matriculados em cursos superiores não gratuitos e com avaliação positiva nos processos conduzidos pelo Ministério da Educação, de acordo com regulamentação própria. (Câmara dos Deputados, 2011b, p. 2)

A C1 compilou os discursos dos parlamentares referentes aos debates sobre os projetos. Foram apresentados nas justificativas os contextos político, social e educacional em que o FIES está inserido para enfatizar a importância da matéria. $\mathrm{O}$ foco era sanar as dúvidas e objeções em relação à matéria proposta. $\mathrm{O}$ teor dos projetos em discussão está relacionado, entre outros: à quitação da dívida dos beneficiários; à inserção de critérios de distribuição de vagas e seleção de estudantes pelas IES privadas; à movimentação de recursos do Fundo de Garantia do Tempo de Serviço (FGTS) para fins de pagamento do saldo devedor do financiamento; ao processo seletivo; e à contratação do financiamento.

\section{EIXO 2: CONTEXTO DE INFLUÊNCIA:}

\section{MOMENTO DE NEGOCIAÇÃO ENTRE OS PARLAMENTARES}

O Eixo 2 abrange apenas a $\mathrm{C} 2$, com o percentual de $22 \%$ do corpus examinado. Esse eixo assinala o processo de negociação entre os partidos, com destaque para as aprovações dos PL e das MP. Conforme Gramsci (2014, p. 24): "O partido político é nada mais do que o modo próprio de elaborar sua categoria de intelectuais 
orgânicos”. Disso resulta a importância do referido eixo, que tem forte relação com o Eixo 1, por se tratar, também, do processo de votação. Entretanto, o segundo eixo se diferencia do primeiro, porque destaca os embates entre os partidos e as bancadas de apoio e oposição ao governo diante da relevância das matérias de liberação de crédito suplementar para o FIES e do prazo de regulamentação final para aprovação ou não destas.

As seis palavras mais representativas da $\mathrm{C} 2-$ a saber, Votação (phi $=61$ ), Provisória $(\mathrm{phi}=41)$, Senhor $(\mathrm{phi}=35)$, Presidente $(\mathrm{phi}=35)$, Medida $(\mathrm{phi}=34)$ e Matéria (phi $=31)$ - destacam o momento em que os deputados e senadores chamam a atenção para a votação em tempo hábil das matérias em trâmite. Trata-se das negociações para que os acordos entre as bancadas sejam estabelecidos.

As políticas educacionais representam cenários de disputas. Com base nisso, observa-se tensão e embate entre as bancadas, como mostra o destaque a seguir:

Sras. e Srs. Parlamentares, nós insistimos ontem na possibilidade de um acordo para que o chamado esforço concentrado, que tinha por objetivo votarmos a PEC $n^{\circ} 300 / 08$, pudesse produzir efeitos positivos, e chegamos a negociar com a Oposição, que concordava em encerrarmos a discussão da Medida Provisória $\mathrm{n}^{\circ} 487$, de 2010, ontem, e votarmos hoje sem obstrução, desde que fosse votada ontem a PEC no 300/08. (Câmara dos Deputados, 2010, p. 36095)

Ao final dos debates, os parlamentares têm de se posicionar quanto à aprovação, à alteração, ao veto parcial ou ao arquivamento das matérias. De acordo com Yang (2015, p. 330): "Por causa dos acordos e [de] outras atividades envolvidas no desenvolvimento de uma política, frequentemente, o texto final de uma política é significativamente diferente do texto provisório inicial”.

O Eixo 2 deu destaque ao processo de votação das MP. O discurso acima deu destaque para a MP no 487, de 2010, que visava à alteração na Lei no 10.260/2001 e previa mudanças substanciais no FIES. Essa MP se tornou ineficaz em outubro de 2010, pois não foi votada em tempo hábil. As demais MP, que tiveram destaque, foram as destinadas à liberação de recursos para o FIES e receberam aprovação, conforme o discurso a seguir:

Temos que aprovar hoje crédito suplementar, na sessão do Congresso Nacional, que destina recursos não somente para o FIES, como também para o Enem. Peço a todos os deputados e senadores que estejam presentes nessa sessão para podermos aprovar esse crédito suplementar, que vai honrar mais de 1 milhão e 800 mil contratos. (Câmara dos Deputados, 2016, p. 18)

Assim como no Eixo 1, os grupos de pressão atuaram por trás dos bastidores, e não houve participação de convidados nesses debates. Ao longo dos sete anos analisados (2010-2016), depreende-se que o MEC não se programou quanto à questão orçamentária do FIES. Os recursos previstos na Lei Orçamentária Anual (LOA) ficaram muito aquém dos valores executados. Para tanto, foi necessária a edição de várias MP, a fim de aprovar créditos suplementares para honrar os milhares de contratos vigentes. Sobre a questão, ressalta-se: 
A suposta crise do FIES (de 2015 em diante, fortemente noticiada na mídia) fez surgir novas demandas dos grupos educacionais, inclusive com forte atuação junto ao Poder Legislativo para a aprovação de créditos orçamentários suplementares para o programa. (Santos Filho, 2016, p. 216)

Durante a trajetória do FIES, os discursos apontam que o programa foi se tornando uma política altamente mercadológica, e as duas Casas são responsáveis por grande parte desse processo. Os estudos de avaliação de programas públicos são escassos:

Tanto ex-ante, para definir a necessidade de criação de uma nova política; quanto ex-post, para checar se tal política está gerando os resultados desejados e para comparar seus custos a seus benefícios. As ações parecem decorrer de pressões políticas e impressões superficiais [sobre a relevância ou não de um programa em detrimento de outro]. (Mendes, 2015, p. 8)

Mendes (2015) cita o FIES como exemplo dessa sistemática. Entre 2010 e 2014, em apenas cinco anos, os gastos saltaram de $\mathrm{R} \$ 1$,2 bilhão para $\mathrm{R} \$ 13,8$ bilhões. Algumas das IES parceiras se tornaram verdadeiras potências empresariais, com ações na bolsa de valores em ascensão e com altas margens de lucro, advindas dos recursos do programa.

\section{EIXO 3: ARENA DE GOVERNANÇA: RELAÇÕES DE FORÇA, PODER, LOBBIES E CONTRADIÇÕES}

O Eixo 3 compreende o maior percentual do corpus examinado pelo Alceste, com 70\% da análise, e é representado por cinco classes: C3 (24\%), C4 (18\%), C5 (11\%), C6 (9\%) e C7 (8\%). Esse eixo retrata a discussão de Gramsci $(1986,2014)$ em torno do Estado ampliado, que envolve articulações, relações de força e poder, lobbies dos empresários da educação e contradições na grande arena de governança do FIES.

A Classe 3 tem a maior representatividade no discurso do eixo e destacou que, no ano de 2015, o FIES foi o mote dos debates propagados pela mídia, pelo Estado (no que se refere à educação) e pela sociedade em geral. O referido ano foi representado pela correlação de forças entre a sociedade política e a sociedade civil, principalmente a mercantil. Como resultado dessa queda de braço, os estudantes foram os maiores prejudicados. Como consequência, o financiamento do ensino superior privado segue sob a prevalência da ótica mercantil.

A análise dessa C3 - cujas seis palavras mais representativas são: Ano 2015 $(\mathrm{phi}=30)$, Eleitoral $(\mathrm{phi}=27)$, Educador $(\mathrm{phi}=18)$, Cortes $(\mathrm{phi}=18)$, Bilhões $(\mathrm{phi}=16)$ e Governo $(\mathrm{phi}=15)$ - revelou a presença de várias redes de atores com perspectivas e interesses antagônicos no que tange ao FIES. O Alceste assinalou o trecho mais representativo da Classe:

Disse a presidente: Querem uma confissão? Vou dizer onde: FIES. Tivemos um erro. $\mathrm{O}$ governo cometeu um erro no FIES. Passou para o setor privado o controle dos cursos. Não fazemos isso com o Prouni, não fazemos com o Enem, não fazemos com ninguém. Isso não é culpa do setor privado. Fomos nós que 
fizemos isso. Em vez de controlar as matrículas, quem controlava era o setor privado. Foi o que disse a presidente. Esta é a síntese do FIES: é um programa bilionário, feito sem o devido planejamento e sem garantias de qualidade de ensino. As universidades viram suas ações dispararem na Bolsa de Valores. (Senado Federal, 2015a, p. 193)

O discurso do senador Álvaro Dias aponta que o próprio governo reconheceu seu erro na condução do FIES ao deixar o controle do programa nas mãos do setor privado. Faltaram planejamento e garantia de qualidade do ensino. Para Burgarelli (2017, p. 51): "Num gesto raro, a mandatária reconheceu, em março de 2015, ter errado na condução do FIES, principalmente no que diz respeito à falta de controle do governo federal sobre as matrículas dos estudantes". O repasse de recursos bilionários fez com que as ações dos grupos educacionais listados na Bolsa de Valores disparassem.

Desde a repercussão da falta de controle sobre o FIES, um conjunto de alterações foi realizado com a finalidade de limitar a quantidade de recursos gastos, mas o setor privado passou a pressionar o governo com o argumento de que o FIES é um programa pouco custoso, conforme destaca o discurso: "Este é o FIES - eu não vou me alongar: isto é para mostrar que, em 2016, se nada fosse feito, o FIES, de todos os recursos da educação, representaria $5 \%$ de todo o orçamento da educação esse ano, o que não é uma coisa enorme" (Senado Federal, 2015c, p. 665). Esse discurso deixa claro que a palavra de ordem é "dinheiro". Não há preocupação com a questão da sustentabilidade do programa (gastos desmedidos), tampouco com a qualidade precária do ensino ofertado, como se ressalta:

E eu gostaria muito de ver uma discussão de alto nível com o governo, explicando por que a educação deixou de ser prioridade e por que eles estão cortando não a verba do FIES, mas o sonho de milhares de brasileiros que querem, sim, ter acesso ao Ensino Superior. (Câmara dos Deputados, 2015a, p. 309)

As discussões em torno de uma política tão importante como o FIES não devem se resumir à oportunidade de lucro, como se vê no discurso dessa Classe. São fundamentais as questões orçamentárias e de planejamento; o sonho e as expectativas dos jovens de ter acesso e concluir o Ensino Superior; os critérios estabelecidos para a oferta do financiamento; e a questão do endividamento das famílias e da inadimplência.

Assim como a C3, a C4 foca no cenário de 2015. No entanto, destaca as implicações da crise financeira e dos novos critérios estabelecidos para os novos contratos no ano em discussão. Nessa $\mathrm{C} 4$, as palavras mais importantes são: Estudantes ( $\mathrm{phi}=34)$, Mensalidade ( $\mathrm{phi}=23)$, Inscrições ( $\mathrm{phi}=22)$, Novos $(\mathrm{phi}=22)$, Renovação (phi = 22) e Ano 2015 (phi = 22).

Esse novo contexto de diminuição de oferta de contratos atingiu diretamente os estudantes e surpreendeu, de forma negativa, as IES, as quais esperavam formalizar mais contratos que no ano anterior (2014). Ao final de 2015, foram formalizados 287 mil contratos, o que correspondeu a 39\% dos 732 mil contratos 
registrados em 2014. O MEC admitiu que a verba destinada ao programa acabou, conforme destaca o discurso a seguir:

O Ministério da Educação admite que a verba para novos contratos está esgotada. Alunos que tinham a esperança de conseguir o financiamento, agora, terão de abandonar o curso por não poderem pagar. Há jovens que não pagaram as três primeiras mensalidades do ano e que já totalizam uma dívida na universidade de cerca de R\$9 mil. (Senado Federal, 2015b, p. 150)

Muitos estudantes calouros tiveram de abandonar os cursos, pois não conseguiram o financiamento, ou tiveram de contratar financiamentos privados, que têm juros elevados. O deputado Atineu Cortês citou o caso de uma estudante que não conseguiu contratar o FIES e contratou o programa de crédito educativo Pravaler:

Depois de tentativas recorrentes desde fevereiro, a estudante do primeiro semestre de Pedagogia, Carolina Canedo, de 20 anos, desistiu do benefício e decidiu recorrer ao financiamento privado. Ela paga cerca de $\mathrm{R} \$ 230$, metade do valor da mensalidade. $O$ restante será pago após a formatura, em até 4 anos, com correção da inflação. Os juros do Pravaler, maior programa privado de crédito universitário do País, podem chegar a 2,19\% ao mês. (Câmara dos Deputados, 2015c, p. 143)

Com a crise do FIES em 2015, muitas IES e instituições financeiras viram uma oportunidade de lucro e criaram diversos programas de crédito estudantil privado. Além disso, tais instituições têm feito forte investimento em marketing para atrair os estudantes. Os alunos que conseguiram renovar os contratos com o FIES tiveram mais um obstáculo: "Para agravar o problema, as instituições privadas que ofereciam o programa passaram, em muitos casos, a cobrar valores maiores do aluno que aderiu a ele e a aplicar aumentos de mensalidades acima do normal" (Câmara dos Deputados, 2015e, p. 3). Em relação ao aumento das mensalidades do FIES: "Houve tratamento privilegiado às instituições privado-mercantis de Ensino Superior, que puderam fixar as mensalidades livremente, sem nenhuma vinculação a índices inflacionários para o cálculo dos valores a serem pagos pelos alunos financiados" (Santos Filho, 2016, p. 174).

No início de 2015, o MEC limitou o aumento das mensalidades em 6,4\%, e as IES que tiveram alta acima desse percentual ficaram impedidas de aditar os contratos. As IES entraram na Justiça e ganharam a causa, pois, de acordo com a Lei no 9.870/1999 (Brasil, 1999), compete à instituição a aplicação dos reajustes, os quais devem ser baseados no planejamento orçamentário a ser executado durante o ano letivo. Quando os elos da rede de governança do FIES começam a enfraquecer ou apresentar um "equilíbrio instável"(Fairclough, 2001), o setor privado constrói novas alianças com o objetivo de manter sua hegemonia na esfera do Ensino Superior.

$\mathrm{Na}$ C5, os discursos deram relevo aos programas direcionados à Educação Superior e ao Ensino Técnico e Profissionalizante instituídos nos governos dos presidentes Lula e Dilma. As palavras mais representativas da Classe - ProUni ( $\mathrm{phi}=42)$, Universidade $(\mathrm{phi}=25)$, Ciência sem Fronteiras ( $\mathrm{phi}=24)$, Acesso (phi =22), Cota $(\mathrm{phi}=21)$ e Lula $(\mathrm{phi}=20)$ - apontam o caráter social das políticas 
implementadas. Aqui, foram realçados 69 discursos. Destes, 48 (70\%) foram de deputados e senadores do Partido dos Trabalhadores (PT). Os parlamentares destacaram as mudanças instituídas no FIES no último governo do presidente Lula (2010 - ano de eleição da presidente Dilma):

A universalização do Enem é uma realidade e um sinal de democratização do acesso a programas federais, como o Sistema de Seleção Unificada (Sisu), o Programa Universidade para Todos (Prouni), o Financiamento Estudantil (FIES), o Programa Nacional de Acesso ao Ensino Técnico e Emprego (Pronatec) e o programa Ciência sem Fronteiras. (Senado Federal, 2014c, p. 194)

Os discursos apontam que os governos de Lula e Dilma caminharam rumo à democratização do acesso ao Ensino Superior e que os filhos dos pobres passaram a ocupar os espaços acadêmicos, com real possibilidade de ascensão verticalizada, enfatiza o deputado Márcio Macêdo (Câmara dos Deputados, 2014a, p. 116).

Como política pública, o FIES promoveu avanços sociais e educacionais significativos. Todavia, ao mesmo tempo, promoveu prejuízos econômicos e sociais ao entregar ao mercado o controle da maior parte do Ensino Superior do País, bem como ao endividar jovens e suas famílias.

O FIES produz um consentimento resignado que naturaliza a desigualdade de acesso ao ensino de Nível Superior. Afinal, "não se democratiza e não se garante o direito constitucional, pois seu investimento está na expansão do capital privado, e não na expansão massiva da universidade pública, como requer uma verdadeira democratização do ensino" (Vituri, 2014, p. 146). Para o governo do PT, o que importa são os números:

Há uma matéria no Valor Econômico dizendo que temos 1,6 milhão de jovens pobres frequentando universidades pelo Prouni e pelo FIES - 30\% do total de estudantes universitários no País! Esta é uma mudança concreta na vida do povo. É por isso que o presidente Lula sorri, que a presidenta Dilma sorri. (Senado Federal, 2014a, p. 210)

A forma com que a política do FIES foi construída evidencia que o Estado está situado em uma rede de governança. Por isso, não cabe considerá-lo como um ator secundário. $\mathrm{O}$ Estado é o ator central, que se posiciona estrategicamente na rede de relações sociais. O Estado é um aparelho que, dependendo de seus objetivos, estabelece limites bem próximos ou distantes fundamentais nas relações público-privadas, e as decisões tomadas definem as condições de acesso aos recursos e aos setores públicos. Nessa arena, enquanto alguns atores são privilegiados, outros têm seus direitos negados ou parcialmente atendidos.

A C6 retrata os desafios do FIES dentro das diferentes perspectivas concernentes à educação pública e à educação privada, conforme os discursos e as palavras mais significativos: PNE (phi = 40), Qualidade (phi = 31), Privada (phi = 29), Meta (phi = 25), Setor ( $\mathrm{phi}=21$ ) e Pública ( $\mathrm{phi}=21)$. Essa Classe compilou 56 discursos. Destes, $12(21,5 \%)$ são dos representantes das associações dos professores e dos estudantes e 12 (21,5\%) são do deputado Ivan Valente, do Partido Socialismo e Liberdade (PSOL). 
As associações representativas dos trabalhadores em educação e dos estudantes defendem que o Estado deve perseguir o interesse público, ou seja, priorizar a educação pública. Em contrapartida, a sociedade mercantil prega que o Estado deve fomentar e financiar a educação privada. Não é por menos que $88,2 \%$ das IES brasileiras são privadas. Estas contam com $75,4 \%$ dos estudantes matriculados no Ensino Superior (Brasil, 2019). Conforme Virgínia Barros, presidente da UNE:

O fundamental, do nosso ponto de vista, é inverter essa lógica, para que consigamos caminhar em uma perspectiva de que a maioria das matrículas, nos próximos 10 anos, seja na rede pública, por ser a rede que, de fato, persegue o tripé ensino, pesquisa e extensão determinado pela nossa própria Constituição Federal. (Senado Federal, 2013, p. 1271)

Para chegar ao cenário proposto nesse discurso, é necessário que as políticas em curso mudem seus objetivos e passem a priorizar a educação pública. A C6 assinala o quanto o FIES tem sido benéfico à "financeirização da educação", que está figurada pelas fusões e aquisições entre as IES privadas. As redes educacionais "viraram verdadeiras fábricas de diplomas, sem ensino, pesquisa e extensão" (Câmara dos Deputados, 2013, p. 36895).

O FIES é uma política de financiamento para a democratização do acesso à Educação Superior, que acaba se pautando no endividamento público. Essa forma de financiamento:

Reforça o caráter de financeirização da Educação Superior, pois o fundo público é utilizado como pressuposto para a expansão do capital financeiro, tendo em vista que os títulos emitidos são negociáveis (certificados do Tesouro Nacional), podendo sofrer especulação financeira. (Santos Filho, 2016, p. 211)

Ademais, tais títulos contribuem sobremaneira para a saúde financeira das instituições parceiras, pois "estão sujeitos à recompra por parte do governo federal ou podem ser utilizados para compensar dívidas das instituições privado-mercantis de ensino com a Previdência Social", acrescenta Santos Filho (2016, p. 211). O discurso a seguir corrobora o exposto:

[Nesta] semana, nós tivemos a notícia da compra das Faculdades Metropolitanas Unidas pelo grupo Laureate por $\mathrm{R} \$ 1$ bilhão, uma nova fusão e concentração de escolas particulares. Há alguns meses, criava-se o maior grupo privado do País, chamado Kroton, que comprou a Anhanguera e Anhembi Morumbi. Estes são os verdadeiros receptores do FIES e do Prouni: empresas estrangeiras, fundos privados estrangeiros, que visam ao lucro. Esses são os beneficiários. (Câmara dos Deputados, 2013, p. 36895)

$\mathrm{Na}$ arena educacional, os grupos de capital aberto vivenciaram uma expansão acentuada nos anos de 2010 a 2015. Nara Teixeira, representante da Contee, questiona, entretanto, a qualidade da educação que as IES privadas oferecem. Segundo ela, em 2015, a Kroton teve um lucro líquido da ordem de R $\$ 244$ milhões: 
"A contrapartida para nós, a qualidade, não é apenas os estudantes terem acesso a uma universidade, mas que tipo de universidade, que tipo de educação esses alunos estão recebendo" (Câmara dos Deputados, 2015b, p. 27).

Em 2016, o governo disponibilizou as vagas de acordo com o conceito dos cursos. Assim, por exemplo, $35 \%$ dos financiamentos foram para cursos com conceito 5 , e $10 \%$, para cursos recém-autorizados.

A última Classe do Eixo 3, a C7 - cujas palavras mais significativas foram: Profissionais $(\mathrm{phi}=47)$, Estados $(\mathrm{phi}=23)$, Municípios $(\mathrm{phi}=22)$, Saúde $(\mathrm{phi}=$ 22), Área (phi = 22) e Mercado (phi = 18) -, compilou os discursos relacionados à defesa da ampliação do benefício de abatimento da dívida do FIES para profissionais formados em Segurança Pública, Enfermagem, Nutrição, entre outros.

Em 2010, a Lei no 12.202, no artigo 6B, instituiu que o FIES abateria, mensalmente, $1 \%$ do saldo devedor dos estudantes que exercessem as profissões: professor da rede pública de Educação Básica, com jornada de, no mínimo, 20 horas semanais; e médico integrante de equipe de saúde da família, com atuação em áreas e regiões definidas como prioritárias pelo Ministério da Saúde (Brasil, 2010).

Os parlamentares queriam ampliar esse benefício a partir da celebração de um acordo entre União, Estados e Municípios, no sentido de que os estudantes (durante o curso ou após sua conclusão) pudessem prestar serviços nas áreas do curso de Graduação. Com essa medida, o FIES poderia ser pago com trabalho, compatibilizando o curso com a atividade que o estudante exerceria durante a Graduação, conforme destaca o discurso a seguir: "Esses alunos do FIES poderiam muito bem, por meio de um acordo celebrado entre União e Estados, prestar serviços não só nas escolas públicas de todo o País, mas em hospitais e órgãos de defesa do consumidor" (Câmara dos Deputados, 2011a, p. 9572).

Para o deputado Izalci, essa medida poderia ajudar os governos estaduais, os municípios e os prefeitos a terem um melhor padrão de qualidade no trabalho público. Na mesma linha de pensamento, o deputado Wadson Ribeiro (PCdoB-MG) criou o Projeto de Lei no 2.659/2015 (Câmara dos Deputados, 2015d) com a finalidade de ampliar o abatimento de saldo devedor mediante prestação de serviço no Sistema Único de Saúde para egressos de cursos superiores da área da saúde: Medicina, Odontologia, Enfermagem, Farmácia, Nutrição, Fonoaudiologia, Fisioterapia, Psicologia e Terapia Ocupacional. Para o deputado, o projeto fomentará a democratização da Educação Superior brasileira, bem como contribuirá com o cumprimento da Meta 12 do PNE e com a elevação das taxas de matrícula nesse nível de ensino (Câmara dos Deputados, 2015d).

No geral, os discursos apresentados evidenciam que a falta de uma avaliação rigorosa do FIES, que mensure os potenciais ganhos e custos das políticas educacionais, "pode representar um aumento de custos sem retorno social, se os programas federais voltados à educação forem ineficientes. Nesse caso, a sociedade estaria pagando mais impostos para custear serviços que não lhes dão o esperado retorno" (Mendes, 2015, p. 8). De fato, o que se vê nos discursos são defesas pessoais ou corporativas travadas nos embates dos representantes públicos e privados, cujas consequências não parecem favorecer, efetivamente, a educação pública brasileira. 


\section{RESULTADOS DA ANÁLISE}

$\mathrm{Na}$ trama do FIES, os nós mais conflitantes giram em torno da questão de os gastos públicos serem direcionados ao Ensino Superior público ou privado, da qualidade ofertada pelas IES privadas, da contribuição do programa para a financeirização da educação e da sua relevância social. Nas palavras de Ball (2014, p. 33, grifo do original): "As relações de rede são opacas, consistindo, em boa parte, de trocas sociais informais, negociações e compromissos que se constituem nos bastidores". Depreende-se que, para atender as demandas do setor privado, o Estado instituiu várias medidas flexíveis em 2010, sem prévia avaliação das implicações dessas mudanças. No campo da análise de políticas, nota-se que não houve planejamento financeiro tampouco previsão dos impactos econômicos e sociais.

Em 2010, a Lei no 12.202 foi aprovada pelo Congresso Nacional e mudou completamente as regras do FIES, impactando diretamente nos recursos da União para a educação. Em 2014, entre fevereiro e agosto, o Congresso Nacional aprovou MP para abrir crédito extraordinário ao FIES. Quando os gastos do programa cresceram de forma desenfreada, o MEC editou a Portaria Normativa $\mathrm{n}^{\circ} 21$, de 26 de dezembro de 2014. As regras passaram a valer em 2015. Desse momento em diante, os representantes do setor privado passaram a fazer reuniões constantes com o MEC e o FNDE e a pressionar os parlamentares para que a pasta voltasse atrás.

$\mathrm{O}$ fato é que o número de contratos diminuiu consideravelmente. No entanto, as IES privadas continuaram recebendo recursos bilionários devido ao número de contratos vigentes. Só no ano de 2016, foram executados R $\$ 18$ bilhões. Ficou claro que, de 2010 a 2014, "o FIES financiou os cursos superiores de mais de 1,3 milhão de estudantes, que têm até 18 meses após a formatura para começar a pagar pela sua formação" (Senado Federal, 2014b, p. 22).

Na visão do senador Paim, devemos comemorar, pois a política alcançou seu objetivo de democratização do Ensino Superior no Brasil ao passo que colocou os "favelados" na universidade: "Nas universidades, nós já vemos negros, brancos, índios, pobres, favelados festejando o título de Doutor, de Mestre, de Nível Superior. O que é isso senão a democratização do ensino no Brasil por que todos nós tanto ansiamos e com o que tanto sonhamos?" (Senado Federal, 2014b, p. 22).

Em contrapartida, o discurso do senador, assim como o da maioria, não questiona se quem tem acesso à Educação Superior via FIES também terá condições de arcar com os custos. Outras questões igualmente não fazem parte das preocupações da maioria dos representantes políticos, tais como: Quais são os cursos a que os estudantes de baixa renda têm acesso por meio do FIES? Qual é a qualidade dos cursos? Após a conclusão do curso, esses estudantes conseguem emprego? Qual é o índice de inadimplência? As famílias estão conseguindo arcar com a dívida?

Segundo Virgínia Barros, presidente da UNE (Senado Federal, 2015c, p. 361): "O FIES, em muitas ocasiões, tem servido como segurança econômica para que as universidades possam fazer as suas fusões, [os] seus processos de abertura de capital no mercado financeiro". O crescimento dos conglomerados educacionais está atrelado à "hábil diretriz que apresenta forte componente social e inegável favorecimento do capital”, destaca Malvessi (2017, p. 76). 
Segundo o deputado Ivan Valente: "Nós não podemos continuar financiando a educação privada enquanto sucateamos o ensino público no nosso País. [...] Esse dinheiro aqui [do FIES] vai alimentar os grandes conglomerados que viraram grandes negócios" (Câmara dos Deputados, 2014b, p. 356).

Para Malvessi (2017), falta às entidades governamentais cobrar, isto é, instituir um mínimo de critérios referentes aos ganhos de receita das empresas educacionais de capital aberto. $\mathrm{O}$ intuito seria elevar a qualificação dos docentes; estabelecer uma quantia mínima para aplicação em projetos de pesquisa e desenvolvimento do ensino; e exigir um nível mínimo de melhoria contínua do Ensino Superior como contrapartida aos recursos recebidos. Será difícil ver isso acontecer, pois "os donos das instituições privadas lucrativas possuem articulações em todos os partidos políticos para preservação de seus interesses. Isso lhes permite travar qualquer tentativa de regulação social efetiva” (Almeida, 2017, p. 117). O Estado detém o controle da "distribuição de vagas, alterando-se apenas a maneira de como essa distribuição é realizada, mantendo-se a essência e a dinâmica do privilégio para uns poucos (empresários educacionais e governo) em detrimento de alguns muitos (alunos-sujeitos)" (Vituri, 2014, p. 145).

O FIES é uma política pública que teve sua gênese justificada no anseio da população carente, que pleiteava o acesso ao Ensino Superior, e se desenvolveu atendendo aos interesses dos empresários da educação, que viram nessa política uma oportunidade de lucro e de consolidação do setor. Depreende-se que o curso dessa política tem forte relação do MEC e do Congresso Nacional com o segmento privado-mercantil, que se tornou um grande potencial empresarial ao formar os conglomerados.

\section{CONSIDERAÇÕES FINAIS}

As análises realizadas com o emprego do Alceste se mostraram cruciais ao apresentar a fala dos parlamentares e convidados na defesa de seus interesses, revelando os núcleos de significação em jogo. Observa-se que o Alceste assinalou os acordos e as correlações de força impressas no FIES dentro do Congresso Nacional. Não foi fácil visualizar as negociações entre as redes, pois estas se constituem, geralmente, nos bastidores. Os conflitos ficam mais aparentes, pois estes acontecem quando cada rede de atores se posiciona durante as audiências.

A análise dos discursos aponta que, no jogo do FIES, estão presentes várias redes de atores com perspectivas e interesses antagônicos. As associações representativas dos trabalhadores em educação e dos estudantes (Contee, Andes e UNE) e alguns parlamentares defendem a bandeira de que o Estado deve perseguir o interesse das massas; priorizar a educação pública; estabelecer contrapartidas para as IES parceiras do FIES; e dar mais relevância ao caráter social do programa.

Em contrapartida, a sociedade mercantil (representada pela Anup, pela Anaceu e pela Fenep - instituições que constituem o Feresp) e grande parte dos parlamentares pregam que o Estado deve fomentar as parcerias público-privadas; promover a oferta de ensino pela via privada; dar mais autonomia ao setor; permitir a criação de uma agência regulatória para fiscalizar o setor, que seja independente do MEC; e aumentar o número de contratos, ou seja, os gastos com o programa. 
Ao analisar as relações do Estado com a sociedade civil, Gramsci (2014) procura compreendê-las dentro de um domínio amplo. Sua concepção de Estado ampliado busca identificar as estratégias de dominação e direção que uma classe exerce sobre a outra. Assim, para que uma classe se torne dominante e diretiva, é necessário um processo de persuasão e de convencimento, o qual é mais eficaz que as ações de coerção. Essa parece ser a estratégia dos grupos sociais dominantes na arena do FIES.

Essa dinâmica elucida a instituição das mudanças flexibilizadoras no FIES em 2010, que resultou na expansão do programa sem a existência de planejamento correspondente e sem a efetivação de estudos financeiros que pudessem dar o suporte necessário ao crescimento exponencial. Em que pese a redução do número de contratos a partir de 2015, o FIES ainda requer recursos em uma ordem anual bilionária para a manutenção dos quase dois milhões de contratos ativos, impactando diretamente em sua sustentabilidade e continuidade. A trajetória do FIES aponta a necessidade de um aprofundamento da compreensão acerca dos fenômenos da propagação das parcerias público-privadas e da ascensão da participação de empresários em conselhos e assentos estratégicos nos órgãos do governo federal.

\section{REFERÊNCIAS}

ALMEIDA, W. M. de. ProUni sob balanço: avanços e limites à luz de experiências estudantis na cidade de São Paulo. In:MARINGONI, G. (org.). O negócio da educação: aventurar na terra do capitalismo sem risco. São Paulo: Olho d'Água, 2017.p. 115-127. BALL, S. J. Educação Global S.A.: novas redes políticas e o imaginário neoliberal. Tradução: Janete Bridon. Ponta Grossa: Editora UEPG, 2014.

BARROS, M. W. O. de. FIES: política pública de acesso e permanência no Ensino Superior. 2014. Dissertação (Mestrado Profissional em Políticas Públicas e Gestão da Educação Superior) - Universidade Federal do Ceará, Fortaleza, 2014.

BRASIL. Lei no 9.870, de 23 de novembro de 1999. Dispõe sobre o valor total das anuidades escolares e dá outras providências. Brasília: Presidência da República, 1999. Disponível em: http://www.planalto.gov.br/ccivil_03/leis/19870.htm\#: :text=LEI\%20 No\%2 09.870\%2C\%20DE\%2 023\%20DE\%20NOVEMBRO\%20DE\%20 1999.\&text=Disp\%C3\%B5e\%20sobre\%20o\%20valor\%20total,Art. Acesso em:30 set. 2020.

BRASIL. Lei $\mathbf{n}^{\circ} \mathbf{1 2 . 2 0 2}$, de 14 de janeiro de 2010. Altera a Lei ${ }^{\circ}$ 10.260, de 12 de julho de 2001, que dispõe sobre o Fundo de Financiamento ao Estudante do Ensino Superior - FIES (permite abatimento de saldo devedor do FIES aos profissionais do magistério público e médicos dos programas de saúde da família; utilização de débitos com o INSS como crédito do FIES pelas instituições de ensino; e dá outras providências). Brasília: Presidência da República, 2010. Disponível em: http://www. planalto.gov.br/ccivil_03/_ato2007-2010/2010/lei/112202.htm. Acesso em: 9 jun. 2021. BRASIL.Ministério da Educação. Secretaria de Educação Superior.Fundo de Financiamento Estudantil - FIES. Prestação de contas ordinárias anual - relatório de gestão do exercício de 2016. Brasilia: MEC/Sesu/FIES, 2017. Disponível em: http://portal.mec.gov.br/index. php?option=com_docman\&view=download\&alias=66631-relatorio-gesta-FIES-exercicio2016-pdf\&category_slug=junho-2017-pdf\&Itemid=30192. Acesso em: 30 set. 2020. 
BRASIL. Ministério da Educação. Instituto Nacional de Estudos e Pesquisas Educacionais Anísio Teixeira. Sinopse estatística da Educação Superior 2018. Brasília: MEC/Inep,2019. Disponível em: http://download.inep.gov.br/informacoes_estatisticas/ sinopses_estatisticas/sinopses_educacao_superior/sinopse_educacao_superior_2018.zip. Acesso em: 30 set. 2020.

BURGARELLI, R. Explosão e implosão do FIES: como o Ensino Superior privado virou o centro dos gastos com educação do governo federal. In: MARINGONI, G. (org.). O negócio da educação: aventurar na terra do capitalismo sem risco. São Paulo: Olho d'Água, 2017. p. 37-54.

CÂMARA DOS DEPUTADOS. Diário da Câmara dos Deputados, Brasília, ano LXV, n. 117, 5 ago. 2010. Disponível em: http://imagem.camara.gov.br/Imagem/d/ pdf/DCD05AGO2010.pdf\#page. Acesso em: 9 jun. 2021.

CÂMARA DOS DEPUTADOS. Diário da Câmara dos Deputados, Brasília, ano LXVI, n. 33, 26 fev. 2011a. Disponível em: http://imagem.camara.gov.br/Imagem/d/ pdf/DCD26FEV2011.pdf\#page=. Acesso em: 13 jun. 2021.

CÂMARA DOS DEPUTADOS. Projeto de Decreto Legislativo no 534, de 2011. Susta os efeitos do $\S 7^{\circ}$, do art. $1^{\circ}$ da Portaria ${ }^{\circ} 1$, de 22 de janeiro de 2010, do Ministério da Educação, que veda, em qualquer hipótese, a concessão de financiamento por meio do FIES a cursos superiores ministrados na modalidade de ensino a distância (EAD). Brasília: Câmara dos Deputados, 2011b. Disponível em: https://www.camara. leg.br/proposicoesWeb/prop_mostrarintegra?codteor=948630\&filename=Tramitac ao-PDC+534/2011. Acesso em: 9 jun. 2021.

CÂMARA DOS DEPUTADOS. Diário da Câmara dos Deputados, Brasília, ano LXVIII, n. 148, 29 ago. 2013. Disponível em: http://imagem.camara.gov.br/Imagem/d/ pdf/DCD0020130829001480000.PDF\#page=. Acesso em: 13 jun. 2021.

CÂMARA DOS DEPUTADOS. Diário da Câmara dos Deputados, Brasília, ano LXIX, n. 79, 29 maio 2014a. Disponível em: http://imagem.camara.gov.br/Imagem/d/ pdf/DCD0020140529000790000.PDF\#page=. Acesso em: 13 jun. 2021.

CÂMARA DOS DEPUTADOS. Diário da Câmara dos Deputados, Brasília, ano LXIX, n. 195, 17 dez. 2014b. Disponível em: http://imagem.camara.gov.br/Imagem/d/ pdf/DCD0020141217001950000.PDF\#page=. Acesso em: 13 jun. 2021.

CÂMARA DOS DEPUTADOS. Diário da Câmara dos Deputados, Brasília, ano LXX, n. 44, 25 mar. 2015a. Disponível em: http://imagem.camara.gov.br/Imagem/d/ pdf/DCD0020150325000440000.PDF\#page=. Acesso em: 9 jun. 2021.

CÂMARA DOS DEPUTADOS. Diário da Câmara dos Deputados, Brasília, ano LXX, n. 45, 26 mar. 2015b. Disponível em: http://imagem.camara.gov.br/Imagem/d/ pdf/DCD0020150326000450000.PDF\#page=. Acesso em: 13 jun. 2021.

CÂMARA DOS DEPUTADOS. Diário da Câmara dos Deputados, Brasília, ano LXX, n. 67, 30 abr. 2015c. Disponível em: http://imagem.camara.gov.br/Imagem/d/ pdf/DCD0020150430000670000.PDF\#page=. Acesso em: 13 jun. 2021.

CÂMARA DOS DEPUTADOS. Projeto de Lei no $\mathbf{2 . 6 5 9}$, de 2015. Altera a Lei ${ }^{\circ}$ 10.260, de 12 de julho de 2001, que dispõe sobre o Fundo de Financiamento Estudantil 
- FIES, para ampliar a possibilidade de abatimento de saldo devedor, mediante prestação de serviço no Sistema Único de Saúde, para egressos de cursos superiores de Medicina, Odontologia, Enfermagem, Farmácia, Nutrição, Fonoaudiologia, Fisioterapia, Psicologia e Terapia Ocupacional. Brasília: Câmara dos Deputados, 2015d. Disponível em: https:// www.camara.leg.br/proposicoesWeb/prop_mostrarintegra;jsessionid=0D1C6FAD6D 48BBC2DC63382136364F0F.proposicoesWebExterno1?codteor=1373229\&filename $=$ PL+2659/2015. Acesso em: 30 set. 2020.

CÂMARA DOS DEPUTADOS. Projeto de Lei no 3.952, de 2015. Altera a Lei ${ }^{\circ}$ 10.260, de 12 de julho de 2001 (Lei do Fundo de Financiamento ao Estudante do ensino Superior - FIES) para tornar obrigatória a concessão dos benefícios deste programa às pessoas que dele necessite. Brasília: Câmara dos Deputados, 2015e. Disponível em: https://www.camara.leg.br/proposicoesWeb/prop_mostrarintegra;jsessionid=node0cvvs fr211nznkmaj1uo5n0r418174909. node0?codteor=1423129\&filename=PL+3952/2015. Acesso em: 13 jun. 2021.

CÂMARA DOS DEPUTADOS. Discursos e notas taquigráficas. Discursos proferidos em plenário. Brasília: Câmara dos Deputados, 2010-2016. Disponível em: http://www.camara.leg.br/internet/sitaqweb/resultadoPesquisaDiscursos.asp?txOrad or $=\& \operatorname{txPartido}=\& \mathrm{txUF}=\& d \mathrm{dt}$ Inicio $=01 \% 2 \mathrm{~F} 01 \% 2 \mathrm{~F} 2010 \& \mathrm{dtF} \mathrm{Fm}=31 \% 2 \mathrm{~F} 12 \% 2 \mathrm{~F} 2016$ $\&$ tx Texto $=\&$ txSumario $=$ FIES\&basePesq $=$ plenario $\&$ CampoOrdenacao $=\mathrm{dt}$ Sessao $\& \mathrm{P}$ ageSize=50\&TipoOrdenacao=DESC\&btnPesq=Pesquisar. Acesso em: 30 set. 2017.

CÂMARA DOS DEPUTADOS. Diário da Câmara dos Deputados, Brasília, ano LXXI, n. 184, 19 out. 2016. Disponível em: http://imagem.camara.gov.br/Imagem/d/ pdf/DCD0020161019001840000.PDF\#page=. Acesso em: 13 jun. 2021.

COUTO, V. P. C. O acesso à educação superior na percepção de concluintes do Ensino Médio: um estudo de sua trajetória e aspirações. 2008. Dissertação (Mestrado em Educação) - Universidade Católica de Brasília, Brasília, 2008.

CRUZ, S. M. S. S. Avaliação da Educação Superior: um estudo comparativo do Brasil e do México. 2013. Tese (Doutorado em Educação) - Universidade Nove de Julho, São Paulo, 2013.

DUARTE, I. F. Impactos de financiamento estudantil sobre encargos escolares: consequências do FIES. 2014. Dissertação (Mestrado em Economia) - Pontifícia Universidade Católica do Rio de Janeiro, Rio de Janeiro, 2014.

FAIRCLOUGH, N. Discurso e mudança social. Brasília: Editora Universidade de Brasília, 2001.

GRAMSCI, A. Concepção dialética da história. Tradução: Carlos Nelson Coutinho. 3. ed. Rio de Janeiro: Civilização Brasileira, 1986.v. 12. (Coleção Perspectivas do Homem). GRAMSCI, A. Cadernos do cárcere. Tradução: Carlos Nelson Coutinho. 7. ed. Rio de Janeiro: Civilização Brasileira, 2014. v. 2. (Os Intelectuais. O Princípio Educativo).

MALVESSI, O. Análise econômico-financeira de empresas do setor da educação. In: MARINGONI, G. (org.). O negócio da educação: aventurar na terra do capitalismo sem risco. São Paulo: Olho d'Água, 2017. p. 75-104.

MENDES, M. Boletim Legislativo no 26, de 2015 - A despesa federal em educação: 2004-2014. Brasília: Senado Federal, 2015. Disponível em: https://www12.senado. 
leg.br/publicacoes/estudos-legislativos/tipos-de-estudos/boletins-legislativos/bol26. Acesso em: 30 set. 2020.

MOURA, T. Políticas públicas para o Ensino Superior brasileiro 2003-2014, uma análise do ProUni e FIES. 2016. Dissertação (Mestrado em Educação) - Universidade Tuiuti do Paraná, Curitiba, 2016.

OLIVEIRA, Z.R. B. B. O crédito educativo: mecanismos de distribuição e percepção de dirigentes e alunos de IES privadas sobre sua contribuição para a expansão da Educação Superior. 2008. Dissertação (Mestrado em Educação) - Universidade Católica de Brasília, Brasília, 2008.

SANTOS,M.J.L.S.Políticas públicas e Direito: democratização do acesso ao Sistema Federal de Ensino Superior. 2015. Dissertação (Mestrado Acadêmico em Direito e Desenvolvimento)

- Escola de Direito de São Paulo, Fundação Getulio Vargas, São Paulo, 2015.

SANTOS FILHO, J. R. Financiamento da educação superior privado-mercantil: incentivos públicos e financeirização de grupos educacionais. 2016. Tese (Doutorado em Educação) - Instituto de Ciências da Educação, Universidade Federal do Pará, Belém,2016.

SENADO FEDERAL. Diário do Senado Federal, Brasília, ano LXVIII, Suplemento B, v. 1, n. 212, 19 dez. 2013. Disponível em: https://legis.senado.leg.br/diarios/ ver/18824? sequencia=233. Acesso em: 13 jun. 2021.

SENADO FEDERAL. Diário do Senado Federal, Brasília, ano LXIX, n. 25, 12 mar. 2014a. Disponível em: https://legis.senado.leg.br/diarios/ver/18878?sequencia=210. Acesso em: 13 jun. 2021.

SENADO FEDERAL. Diário do Senado Federal, Brasília, ano LXIX, n. 94, 4 jul. 2014b. Disponível em: https://legis.senado.leg.br/diarios/ver/19003? sequencia=22. Acesso em: 13 jun. 2021.

SENADO FEDERAL. Diário do Senado Federal, Brasília, ano LXIX, n. 184, 12 nov. 2014c. Disponível em: https://legis.senado.leg.br/diarios/ver/19189?sequencia=194. Acesso em: 13 jun. 2021.

SENADO FEDERAL. Diário do Senado Federal, Brasília, ano LXX, n. 45, 9 abr. 2015a. Disponível em: https://legis.senado.leg.br/diarios/ver/19425 ?sequencia=193. Acesso em: 13 jun. 2021.

SENADO FEDERAL. Diário do Senado Federal, Brasília, ano LXX, n. 67, 13 maio 2015b. Disponível em: https://legis.senado.leg.br/diarios/ver/19478?sequencia=150. Acesso em: 13 jun. 2021.

SENADO FEDERAL. Diário do Senado Federal, Brasília, ano LXX, Suplemento A, n. 71, 19 maio 2015c. Disponível em: https://legis.senado.leg.br/diarios/ ver/19488? sequencia=665. Acesso em: 13 jun. 2021.

SENADO FEDERAL. Atividade legislativa. Plenário. Pronunciamentos. Brasília: Senado Federal, [2017]. Disponível em: https:/www25.senado.leg.br/web/atividade/ pronunciamentos. Acesso em: 30 set. 2020.

SILVA, P. P. O novo aluno do Ensino Superior em um contexto neoliberal. 2014. Dissertação (Mestrado em Educação) - Faculdade de Educação, Universidade Estadual de Campinas, Campinas, 2014. 
SOUSA, A.M. G.Financiamento público estudantil do Ensino Superior: uma análise comparativa dos casos do Brasil e de Portugal.2008. Tese (Doutorado em Educação) Faculdade de Educação, Universidade Federal de Goiás, Goiânia, 2008.

VITURI, R. C.I.Fundo de Financiamento Estudantil (FIES) para o Ensino Superior privado: acesso, processos e contradições. 2014. Dissertação (Mestrado em Educação: Currículo) - Pontifícia Universidade Católica de São Paulo, São Paulo, 2014.

XAVIER, D. S. R. Uma análise dos programas de acesso à educação superior nos governos Lula e Dilma. 2016. Dissertação (Mestrado em Economia Política) Pontifícia Universidade Católica de São Paulo, São Paulo, 2016.

YANG, R. Comparações entre políticas. In: BRAY, M.; ADAMSON, B.; MASON, M. (org.). Pesquisa em educação comparada: abordagens e métodos. Brasília: Líber Livro, 2015. p. 319-343.

\section{SOBRE AS AUTORAS}

Aline Veiga dos Santos é doutora em educação pela Universidade Católica de Brasília (UCB).

E-mail: aveigadossantos@gmail.com

Vera Lúcia Jacob Chaves é doutora em educação-conhecimento e inclusão social pela Universidade Federal de Minas Gerais (UFMG). Professora da Universidade Federal do Pará (UFPA).

E-mail: veraluciajacob@gmail.com

Divaneide Lira Lima Paixão é doutora em psicologia pela Universidade de Brasília (UnB). Professora pela Secretaria de Estado de Educação do Distrito Federal (SEEDF).

E-mail: divaneidepaixao@gmail.com

Conflitos de interesse: As autoras declaram que não possuem nenhum interesse comercial ou associativo que represente conflito de interesses em relação ao manuscrito.

Financiamento: $\mathrm{O}$ estudo não recebeu financiamento.

Contribuições dos autores: Administração do Projeto, Análise Formal, Conceituação, Curadoria de Dados, Escrita - Primeira Redação: Santos, A.V.; Chaves, V.L.J. Escrita Revisão e Edição, Metodologia, Software: Paixão, D.L.L. 